\title{
Maximizing habitat connectivity in the mitigation hierarchy. A case study on three terrestrial mammals in an urban environment
}

\author{
Simon Tarabona,b,*, Laurent Bergèsc, Thierry Dutoitb, Francis Isselin-Nondedeub,d \\ a Soberco Environnement, Chemin du Taffignon 69630 Chaponost, France \\ b Institut Méditerranéen de Biodiversité et Ecologie, UMR CNRS-IRD, Avignon Université, Aix-Marseille Université, IUT d'Avignon, \\ 337 chemin des Meinajariés, Site Agroparc BP 61207, 84911 Avignon, cedex 09, France \\ c Université Grenoble Alpes, Irstea, UR LESSEM, 2, rue de la papeterie, BP 76, 38402 Saint-Martin-d'Hères Cedex, France \\ dDépartement Aménagement et Environnement École Polytechnique de l'Université de Tours, UMR CNRS 7324 CITERES 33-35 \\ Allée Ferdinand de Lesseps, 37200 Tours, France
}

\begin{abstract}
Environmental policies and the objective of no net loss highlight the importance of preserving ecological networks to limit the fragmentation of natural habitats and biodiversity loss, especially due to urbanization. In the environmental impact assessment context, habitat connectivity and the spatio-temporal dynamics of biodiversity are crucial to obtaining reliable predictions that can support decision-making. We propose a methodological framework 1) to quantify the overall impact of a development project on the functioning of an ecological network, and 2) to select the best locations for implanting new habitat patches intended to enhance landscape connectivity. The amount of reachable habitat concept was applied to three representative terrestrial mammal species: the red squirrel, the Eurasian badger and the European hedgehog. All three species are recognized as vulnerable to human pressures and potentially affected by the construction of a new stadium in our study site, Lyon (Southern France). The method combines the species distribution model Maxent with the landscape functional connectivity model Graphab. The results showed that using any one of the avoidance and reduction measures on its own was unsuccessful in achieving the objective of no net loss when habitat connectivity is considered. However, the combination of new habitat patches and corridors offered a higher gain than distinct measures. This is especially important in the short term, when new hedgerow plantations have not yet developed enough to be used by the target species. Our findings indicate, first, the need to take the temporal scale into account in environmental impact assessment. We also show that applying the optimal scenario, constructed using a cumulative patch addition followed by a similar process testing a set of potential land-use changes, maximizes habitat connectivity. Our methodology provides a useful tool to increase target species' habitat connectivity within the mitigation hierarchy and to enhance development project design for increased environmental efficiency.
\end{abstract}

\section{Keywords}

Conservation planning, maximum entropy modelling, graph theory, red squirrel, Eurasian badger, European hedgehog 


\section{Introduction}

Preserving biodiversity is a major concern where landscapes are changing rapidly, especially due to urbanization (Antrop, 2004). Urban sprawl, city growth and conurbations are important factors that degrade habitats and fragment landscapes. Such fragmentation and habitat loss have been established as major causes of biodiversity decline over the last decades (Maxwell et al., 2016). If urban expansion continues at the current rate, more than $70 \%$ of all species concerned will be impacted by 2030 in countries with low levels of urban regulation and planning (Huang et al., 2018a). This highlights the importance of environmental planning to limit threats to biodiversity. Regulations in the most industrialized countries impose an environmental impact assessment (EIA) to limit the potential impacts of development projects on the environment and on biodiversity (Bezombes et al., 2017). Environmental policies typically define a goal of no net loss (NNL), or sometimes of net gain, of biodiversity to be achieved through the mitigation hierarchy. The NNL principle refers to a baseline situation (Maron et al., 2018), generally the initial state of the environment before the development project.

Avoidance, reduction and offsetting measures are used to reach this goal. These actions (such as ecosystem restoration) provide biodiversity gains that are supposed to be equivalent to the biodiversity losses from development impacts. Mitigation measures are usually performed in situ for reduction and elsewhere for offsetting by means of habitat restoration or the management of "ecologically important areas", defined as sites containing populations of very vulnerable species (Arlidge et al., 2018). However, offsetting is often much easier in theory than in practice, which makes applying the NNL principle challenging (Quétier et al., 2014). The answer is for all projects to promote impact avoidance and reduction, for instance by selecting an alternative development site or by as far as possible preserving natural habitats and reducing impacts on both species and ecosystem functions (Phalan et al., 2018). For example, two existing habitats can be reconnected in the landscape by planting hedgerows and constructing underground or overhead wildlife crossings (De Montis et al., 2018). Ultimately, biodiversity gains resulting from the whole mitigation hierarchy should compensate for biodiversity losses both in quality and in quantity (Bezombes et al., 2017).

Ecological equivalence is calculated based on the ratio between ecological gains and losses, and is part of environmental impact assessment (EIA) (Gonçalves et al., 2015). Many different assessment methods are used worldwide, but most are accused of not adequately taking into consideration the different scales of biodiversity functioning and the effects of development projects at the landscape scale (Bergsten and Zetterberg, 2013; Bigard et al., 2017). Any landscape element, such as a habitat patch or an ecological corridor, needs to be considered as an integral part of a wider functional network whose integrity allows individuals to move and to exchange genes, and finally populations to survive (Kiesecker et al., 2010). Thus, insufficient consideration of landscape connectivity can lead to irreversible effects on biodiversity (Tallis et al., 2015). Habitat connectivity sensu Saura et al. (2011) (i.e. the 'amount of reachable habitat' concept) is a response to the need to conserve biodiversity in the face of habitat loss and fragmentation (Martensen et al., 2017). 
A better understanding of how species are distributed and how they use the different landscape elements is therefore required to improve assessment of the potential impacts of development projects and to evaluate the effects of mitigation measures. This can be achieved notably by using species distribution models (SDM) and landscape connectivity analysis. SDM relate species distribution records to environmental data and can be used to produce maps of suitable habitats (Elith et al., 2006). Therefore they are increasingly applied to prioritize areas for conservation (Bosso et al., 2018) and support conservation decision-making (GuilleraArroita et al., 2015). Landscape connectivity analysis uses graph-based approaches to map habitat networks and assess habitat connectivity. This method has recently been applied in land-use planning for habitat prioritization and connectivity improvement (Clauzel et al., 2018; Foltête, 2018). In addition, a recentlydeveloped methodological framework combining SDM and spatial graphs has improved assessment of the environmental impacts of development projects, valuable input to decision-making (Duflot et al., 2018; Tarabon et al., 2019). However, although the latter study strongly recommended that the framework be applied to implement appropriate avoidance and reduction measures, this has not yet followed. Such modelling approaches need to be thorough to fully cover all the steps in the mitigation hierarchy, from reevaluating residual impacts in a meaningful way to dimensioning mitigation measures.

In the EIA context, understanding the spatio-temporal dynamics of biodiversity is crucial to obtaining reliable predictions that can guide decision-making. Predictions of biodiversity losses and gains are subject to some uncertainty, despite the implementation of the offset ratio (Moilanen et al., 2009), in particular because during the project design process, benefits to the species from the mitigation measures are usually considered in the short term (ST; generally between 3 and 5 years). However, many naturalist surveys actually report a loss of biodiversity during the first years following development projects. It is well known that plantations like hedgerows only increase landscape connectivity for terrestrial mammal species in the medium term (MT), particularly when they are well-developed, wide and continuous (Dondina et al., 2016).

The aims of this study were 1) to quantify the overall impact of a development project on the functioning of an ecological network, and 2) to assess the ecological gains at landscape scale that result from the avoidance and reduction measures. For this purpose, we combined species distribution modelling and landscape graphs using Maxent and Graphab software and presence points of three mammal species. This methodological framework was intended to help us choose the best locations for new habitat patches that would enhance landscape connectivity for the studied species.

We studied three terrestrial mammals presents in suburban areas, recognized as vulnerable to human pressures and to increasing habitat fragmentation (see references below). We considered these three species as key indicators of suburban biodiversity, i.e. their mere presence indicates the probable presence of many other species that are characteristic of suburban habitats. The three species studied were (1) the Eurasian red squirrel (Sciurus vulgaris L. 1758), an indicator species of well-preserved woodland and forest in the landscape (Adren and Delin, 1994; Avon and Bergès, 2016) but fairly sensitive to urban development (Tannier et al., 2016); (2) the Eurasian badger (Meles meles L. 1758), widely recognized as particularly 
sensitive to habitat loss and to the disruption of connectivity (Bani et al., 2002) and whose populations are either threatened or in decline in the study area (Malèvre, 2017); and (3) the European hedgehog (Erinaceus europeanus L. 1758), adapted to both urban and suburban environments but highly affected by human activities and road development, which have decreased the hedgehog's range area (Ceballos and Ehrlich, 2002) and exposed it to risk from traffic collisions (van de Poel et al., 2015).

\section{Methods}

\subsection{Study site}

The study area is located in the suburbs of Lyon, France. The urban and suburban landscapes have been modified since 2012 by a 161-ha project for a new stadium and its associated developments: extension of a tramway line, creation of an interchange with a national road, construction of public transport lanes and restructuring of an existing street. The city decided to invest in major sports facilities of regional or national stature, in line with the European ambitions of Lyon and its region.

To counterbalance potential impacts on the environment, as an avoidance measure (AM), some small forest patches $(5.9 \mathrm{ha})$ located within the project footprint were preserved. In addition, specific reduction measures (RM) were implemented: plantation of small forest patches of over 0.5 ha, plantation of 8 ha of 10 meterswide multi-strata hedgerows (herbs, shrubs and tree layers), and construction of four wildlife crossings (Fig. 1). Plantations were identified in 2018 using a field-based approach to discriminate plantations too close to disturbance zones (e.g. recreational and tourist areas).

a)

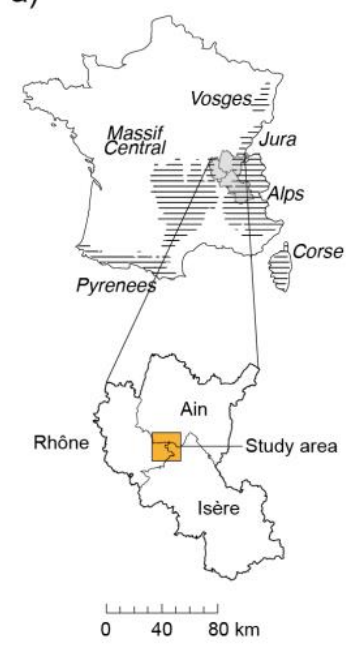

b)

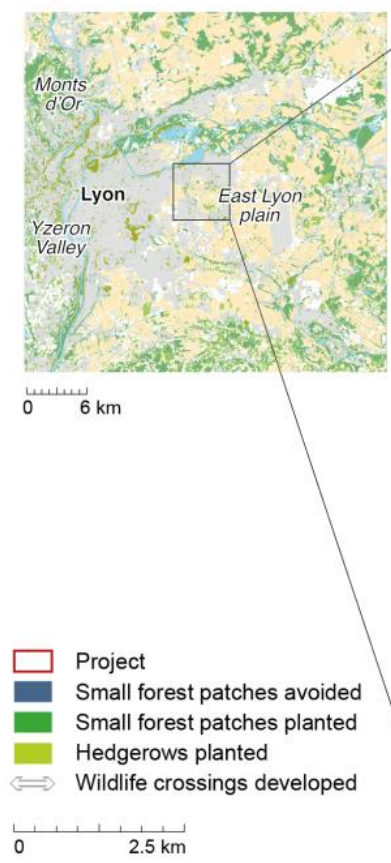

c)

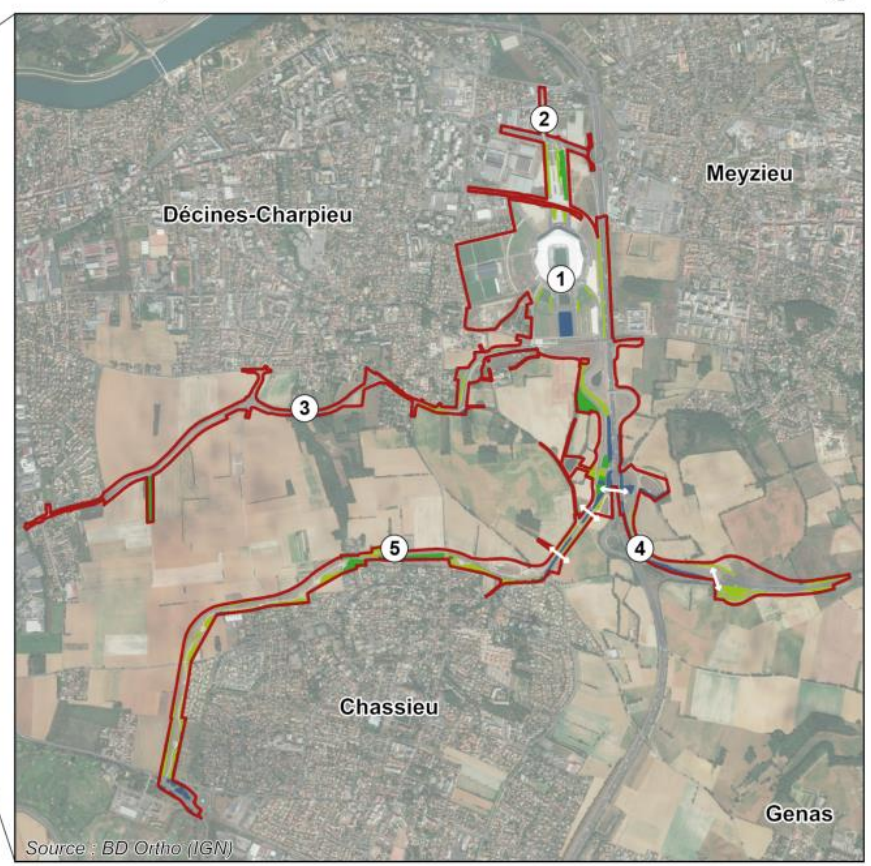

Fig. 1. a, b: Location of the study area at the national and regional scale. c: Aerial view of the new stadium and its associated developments (1: New stadium, 2: Extension of the tramway line, 3: Development of existing street, 4: 
Creation of interchange with national road, 5: Construction of public transport lanes) with specific avoidance and reduction measures listed in Methods Section 2.1 .

\subsection{Identifying habitat patches with species distribution modelling}

In Sections 2.2 and 2.3 of Methods, we largely apply the methodological framework already described in Tarabon et al. (2019, in press). We used maximum entropy modelling Maxent version 3.4.1 (Elith et al., 2011; Phillips et al., 2006) to identify suitable habitats for each studied species and to create a species habitat suitability index (HSI) across the wider study area $\left(1,240 \mathrm{~km}^{2}\right.$; Fig. 1b), to ensure that results would be more robust and less sensitive to sample size.

Occurrence data on the red squirrel, the Eurasian badger and the European hedgehog were obtained from nongovernmental organization (NGO) databases created by the League for the Protection of Birds (LPO Ain, Rhône and Isère sections). The surveys feeding the database were conducted by trained observers (naturalist NGOs, managers of natural areas and other partners) between 2000 and 2011 and every observation (by camera trapping or visual observation) was validated by local experts from the LPO. The databases had 793, 231 and 357 occurrence records for the red squirrel, the Eurasian badger and the European hedgehog, respectively (Appendix S1). To avoid geographical sampling bias in these occurrence data, we implemented a bias file with the package dismo (Hijmans et al., 2017; Team, 2017), calculating a kernel density estimate of sampling effort across the study area. This was required because collaborative databases such as LPO contain observations from different sources or made near urban areas and roads.

Habitat variables and slope (derived from the topography) were extracted from available national databases: BD TOPO ${ }^{\circledR}$ and RGE ALTI ${ }^{\circledR}$ provided by the French National Geographical Institute (IGN), the French Record of Agricultural Plots (RPG) and European Urban Atlas provided by the Global Monitoring for Environment Security project. In line with the literature, we selected twelve categories expected a priori to be the most relevant to the habitat preferences (ecological and biological requirements) of the species. These environmental variables were categorized (Appendix S2) and converted into a $5 \mathrm{~m}$-resolution raster map using ArcGIS 10 (Environmental Systems Research Institute, Inc.). For each variable and raster generated (except for the slope), a value was attributed to each cell corresponding to the closest distance between the centroid of the cell and the nearest patch of the habitat variable. We identified collinearity and estimated the extent of the effect of multicollinearity among explanatory variables with the variance inflation factors (VIF) obtained using the r-squared value of the regression of a given variable against all other explanatory variables. In a stepwise approach, we calculated a VIF for each variable, removed the variable with the highest value and recalculated all VIF values for the new set of variables, until all values were below the threshold (VIF $<10$; usdm package; Naimi et al., 2014; Team, 2017).

A series of Maxent models was implemented with a variety of user-defined settings (i.e. feature classes and regularization multipliers), using software package ENMEval (Merow et al., 2013; Muscarella et al., 2014). A model prediction was generated for each combination of feature class (31 feature classes) and regularization 
multiplier settings (10 regularization multipliers), and the most parsimonious and optimal model was selected based on the corrected Akaike Information Criterion ( $\mathrm{AIC}_{\mathrm{c}}$ ) (Galante et al., 2018; Lobo et al., 2008) from the unpartitioned dataset.

Maxent predictions were evaluated following a $k$-fold cross-validation procedure, wherein species presence points are randomly split into $k$ equalsized subsets to successively serve as test data, while the remaining $k-1$ folds are used as training data (Merow et al., 2013; Thuiller et al., 2009). Models were trained on a random selection of $75 \%$ of occurrences, and then tested on the remaining $25 \%$ to determine the predictive performance of the model. For each training partition, 15 replicates were run (bootstrapping) and the results averaged. Other features were set by default, with a maximum of 2,000 iterations. The outputs of each model were mapped using logistic outputs with continuous probabilities ranging from 0 to 1 (Merow et al., 2013). The performances of final models were evaluated using the true skill statistic (TSS) (Allouche et al., 2006), Cohen's kappa (Monserud and Leemans, 1992) and AUC (Area Under the receiver operating Curve) (Baldwin, 2009) (Appendix S3). The relative contribution of each environmental variable to the model was assessed using a jackknife procedure. This approach excludes one variable at a time when running the model and provides information on the performance of each variable in the model in terms of the extent to which each variable explains the species distribution and how much unique information each variable provides.

Finally, the resulting HSI map was used to define suitable habitat patches as derived from the threshold selection method available in Maxent: maximum training sensitivity plus specificity (MaxTSS). This method has been shown to produce highly accurate predictions (Jiménez-Valverde and Lobo, 2007; Liu et al., 2013). We used the mean logistic threshold value from the 15 runs. Then, the habitat patch outputs were selected using a minimum area to account for the home-range size of the species, which eliminated habitat patches too small to permanently support individuals. A threshold of 0.5 ha was chosen for the red squirrel (Wauters et al., 1994) and the Eurasian badger (Bouniol, 2017) and 0.1 ha for the European hedgehog (Morris, 1988).

\subsection{Connectivity analysis}

Landscape graph analyses were used to evaluate habitat connectivity (Foltête et al., 2012b; Galpern et al., 2011; Pascual-Hortal and Saura, 2006). Habitat connectivity was calculated using the Equivalent Connectivity (EC; Eq. 1) index proposed by Saura et al. (2011), a combined measure of habitat amount and connectivity derived from the Probability of Connectivity index (PC; Saura and Pascual-Hortal, 2007), which is defined as 'the probability that two animals randomly placed within the landscape fall into habitat areas that are reachable from each other':

$$
E C=\sqrt{\sum_{i=1}^{n} \sum_{j=1}^{n} a_{i} a_{j} p_{i j}{ }^{*}}
$$


where $n$ is the total number of patches, and $a_{i}$ and $a_{j}$ are attributes of nodes $i$ and $j$. Habitat patch attributes can be defined in many ways (Saura and Rubio, 2010). Here, connectivity models were improved by integrating habitat patch quality from the habitat suitability index (HSI) value (Decout et al., 2012; Minor and Urban, 2007). Thus, node attributes correspond to the quality-weighted habitat area, i.e. 1 ha of habitat amounts to 1 ha if its average HSI equals 1 , while the same habitat area actually amounts to 0.5 ha if its average HSI is 0.5 . $p_{i j} *$ is defined as the maximum product probability of all possible paths between patches $i$ and $j$ (including single-step paths). The product probability of a path (where a path consists of a set of steps in which no patch is visited more than once) is the product of all the $p_{i j}$ belonging to each step in that path. If patches $i$ and $j$ are close enough, the maximum probability path will be simply the step (direct movement) between patches $i$ and $j\left(p_{i j} *=p_{i j}\right)$. If patches $i$ and $j$ are more distant, the "best" (maximum probability) path would probably comprise several steps through intermediate stepping stone patches, yielding $p_{i j} *>p_{i j}$ (Saura and PascualHortal, 2007). Here, the probability of connection between two patches was based on the least-cost distance between these two patches. Least-cost distance was transformed into probability of connection between patches $i$ and $j$ using a decreasing exponential function, as shown in Eq. 2 (Saura and Pascual-Hortal, 2007).

$$
p_{i j}=e^{-\propto d_{i j}}
$$

where $\alpha$ is a cost distance-decay coefficient: $\alpha$ is usually set so that $p_{i j}=0.5$ for the median or mean dispersal distance of the focal species, or $p_{i j}=0.05$ for the maximum distance dispersal (Saura and Pascual-Hortal, 2007), as here.

Moreover, to ensure comparability, $E C$ index is compared with the sum of area $S$ weighted by average quality. Links between patches were generated with Graphab software, version 2.2 (Foltête et al., 2012a) (see http://thema.univ-fcomte.fr/productions/graphab/), using a least-cost path (LCP) based on landscape matrix permeability (Dale and Fortin, 2010; Etherington and Holland, 2013; Minor and Urban, 2007; Rayfield et al., 2010). The least-cost path is the path of least resistance between two patches (Zeller et al., 2012). It represents the shortest functional connection between habitat patches (Adriaensen et al., 2003) and is currently the method most commonly used to produce connectivity estimates (Simpkins et al., 2018). Six resistance values were attributed to the different landscape classes according to species' ability to cross into and survive within them, regardless of habitat suitability (Appendix S4): highly suitable, suitable, neutral, unfavorable, highly unfavorable or barrier to animal movement (Mimet et al., 2016). Values ranged from 1 (very low resistance, i.e. habitat patches from Maxent output and other landscape elements) to 10,000 (barrier), with four intermediate classes $(50,100,400$ and 800$)$.

The linkages were defined from a land-use map converted into a 5 m-resolution raster map to consider hedgerows, streams or paths, landscape elements which are important for the dispersal of the species studied (for example, Moorhouse et al., 2014). This map of the initial situation ("IS") provided a baseline for assessing impact on habitat connectivity. The habitat connectivity index we used took into consideration a 
maximum cumulative dispersal distance (cost distance) related to medium- and long-term metapopulation dynamics and gene flow. Dispersal distances expressed in metric units were converted into cost units using a linear regression between link topological distance and link cost distance for all the links of the graph, following recommendations in Graphab. Based on the literature, we used the following distances: 5,000 m for the red squirrel (Avon et al., 2014; Wauters et al., 2010), 2,000 $\mathrm{m}$ for the Eurasian badger (Delahay et al., 2000; Do Linh San, 2002; Macdonald and Barrett, 2005) and 4,000 m for the European hedgehog (Berthoud, 1978; Morris, 1984). These distances were converted into 32,061, 6,644 and 32,118 cost units, respectively

\subsection{Assessment of connectivity gain from the different avoidance and reduction measures implemented in} 2012

We applied the same framework, running Maxent and Graphab as previously described but this time based on the following scenarios: without ecological measures (i.e. preliminary outline project ; PO), with avoidance measure only $\left(\mathrm{AM}_{1}\right)$, with $\mathrm{AM}_{1}$ and small forest patches planted $\left(\mathrm{RM}_{1}\right)$, with $\mathrm{AM}_{1}$ and hedgerows planted $\left(\mathrm{RM}_{2}\right)$, with $\mathrm{AM}_{1}$ and wildlife crossings built $\left(\mathrm{RM}_{3}\right)$, and with the full set of avoidance and reduction measures implemented (ARMт). See Fig. 2 for more details.

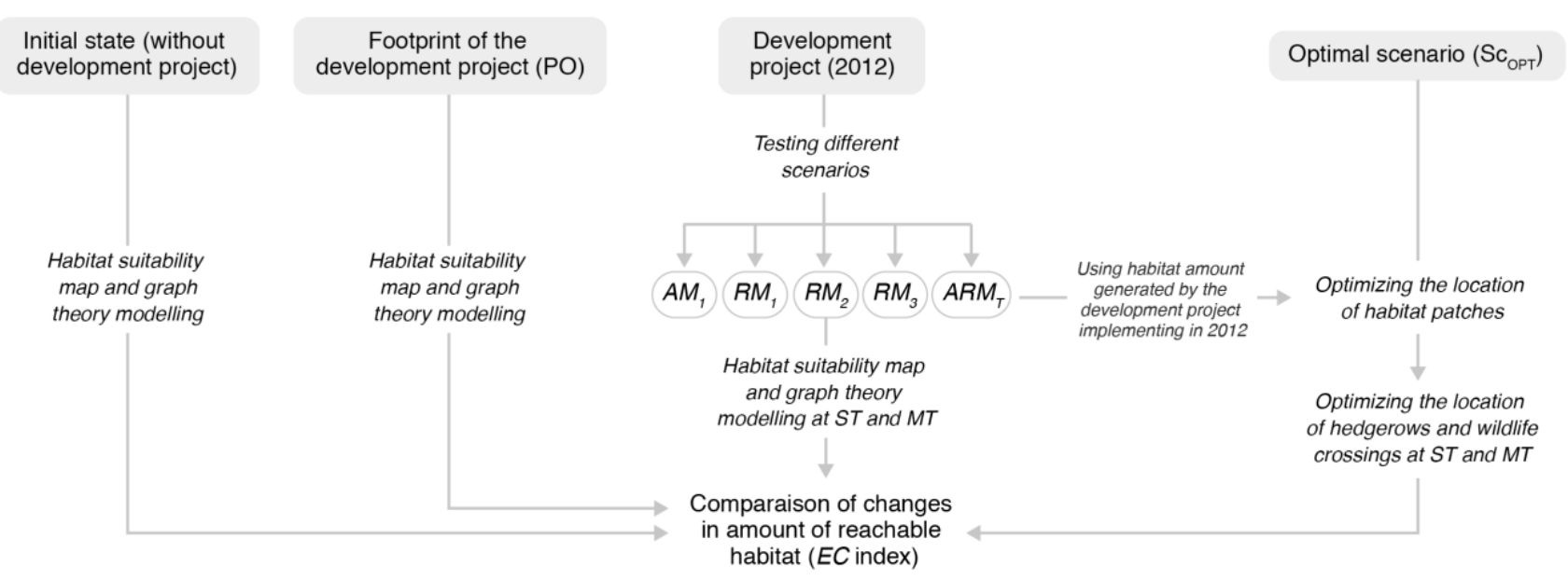

Fig. 2. Methodological framework applied in this study to evaluate changes in amount of reachable habitat between development project scenarios. The method combines the species distribution model Maxent with the landscape functional connectivity model Graphab. See text for more details about parameters used in SDM and spatial graphs (Sections 2.2 and 2.3, respectively), and for meaning of different scenarios (Section 2.4). Time dimension indicated by ST (short term) and MT (medium term).

For the connectivity analysis, resistance values were attributed to the different land-use and land-cover (LULC) classes in the same way as for the initial state (Appendix S4). In each scenario tested, a given resistance cost was applied for each category of LULC (Table 1).

Table 1 Conversion of LULC types into resistance classes and cost values attributed to each category of landcover for the red squirrel, the Eurasian badger and the European hedgehog. ST and MT mean short and medium term, respectively. 


\begin{tabular}{|c|c|c|c|c|}
\hline & & \multicolumn{3}{|c|}{ Ecological function (cost values) } \\
\hline & Categories & Red squirrel & Eurasian badger & European hedgehog \\
\hline Buildings and main roads & $\mathrm{ST} / \mathrm{MT}$ & 800 & 800 & 800 \\
\hline \multicolumn{2}{|l|}{$\begin{array}{l}\text { Secondary roads and other public } \\
\text { infrastructure (without development } \\
\text { projects or ecological measures) }\end{array}$} & 400 & 400 & 400 \\
\hline \multirow{2}{*}{$\begin{array}{l}\text { New small forest patches }\left(\mathrm{RM}_{1}\right) \text { and } \\
\text { hedgerows }\left(\mathrm{RM}_{2}\right) \text { as well as grass } \\
\text { strips at roadsides }\end{array}$} & ST & 50 & 50 & 1 \\
\hline & MT & 1 & 1 & 1 \\
\hline \multirow{3}{*}{$\begin{array}{l}\text { Preserved forest patches (AM) } \\
\text { Wildlife crossings }\left(\mathrm{RM}_{3}\right)\end{array}$} & $\mathrm{ST} / \mathrm{MT}$ & 1 & 1 & 1 \\
\hline & $\mathrm{ST} / \mathrm{MT}$ & 100 & 50 & 50 \\
\hline & Red squirrel & \multicolumn{3}{|c|}{$\begin{array}{l}\text { (Adren and Delin, 1994; Hämäläinen et al., 2018; VINCI } \\
\text { Autoroutes, 2016; Wauters et al., 2010) }\end{array}$} \\
\hline \multirow[t]{2}{*}{ References } & Eurasian badger & \multicolumn{3}{|c|}{$\begin{array}{l}\text { (Bouniol, 2017; Dondina et al., 2016; O’Brien et al., 2016; VINCI } \\
\text { Autoroutes, 2016) }\end{array}$} \\
\hline & European hedgehog & \multicolumn{3}{|c|}{ (Driezen et al., 2007; Moorhouse et al., 2014; Morris, 1984) } \\
\hline
\end{tabular}

For each scenario, the dispersal distance (cost distance) was identical to that used in the initial state. The impact of each scenario on the amount of reachable habitat $\triangle E C$ was simply defined as the relative difference between the initial $E C$ index and the $E C$ index of each scenario.

\subsection{Developing an optimal scenario}

Finally, we determined an optimal scenario (ScOPT) at ST and MT based on the best locations for implementation of habitat patches and reduction measures (hedgerows and wildlife crossings). For the sake of comparability with ARMт, we considered the same habitat amount as that created in 2012 for each species, according to our short term and medium term estimates (Fig. 2): 2.04 and 6.40 ha for the red squirrel, 0.83 and 2.48 ha for the Eurasian badger, and 6.58 and 8.45 ha for the European hedgehog, respectively at ST and MT (Fig. 4). For each species, habitat patches were located in areas with high potential for gains in amount of reachable habitat (see Section 2.6 and Fig. 5d). We also considered four wildlife crossings and 5.5 ha of plantations. The reduction measures offering the highest potential gains in amount of reachable habitat were selected (see Section 2.7 and Fig. 6d).

\subsection{Optimizing the location of habitat patches}

To identify where new habitat patches of 0.5 ha would theoretically maximize connectivity gains, we prioritized cells by means of a cumulative patch addition process available in Graphab. The candidate cells, which have a surface area of $5,000 \mathrm{~m}^{2}$, were restricted to the development project area available for ecological development (Fig. 3a). Particular attention was paid to ensuring that points representing cells were not located where there was a land-use acting as an obstacle, such as a major road (in which case the gain may be overestimated). The stepwise procedure was described in (Foltête et al., 2014) and previously applied in different studies (Clauzel et al., 2015; Mimet et al., 2016). The process first computes the EC index to 
quantify the amount of reachable habitat in the initial state. Then, a search algorithm tests each cell by adding a virtual node to its centroid and adding new links from this node to the other existing nodes. The $E C$ index is recomputed after each cell addition and selects the cell that most greatly increases $E C$. Then, the cell with the second highest contribution to increased $E C$ is determined, and so on. At the end of the process, each cell is associated with a value corresponding to the increase in $E C$. Once single-species prioritization maps were obtained, the different maps were overlaid to spatialize new habitat patches of benefit to all three species. We normalized single-species maps to make them comparable, based on the Jenks method, using ArcGIS 10 (Environmental Systems Research Institute, Inc.).

\subsection{Optimizing the location of hedgerows and wildlife crossings}

We hypothesized that new habitat patches (from the cumulative patch addition process previously described) would be created in cells that maximized habitat connectivity, i.e. in the areas identified by black circles in Fig. 5d. For each species, the total area of habitat patches considered was equivalent to that created for ARMT at ST and MT (Fig. 4). Thus, under the new habitat patch maps, a similar cumulative process was developed to test a set of potential land-use changes (Mimet et al., 2016), using the landmod command in Graphab. We tested 8.5 ha (20 units) of plantations, at ST and MT, and 23 wildlife crossings located throughout the footprint of the project (Fig. 3b), i.e. along roadsides for hedgerows and within road infrastructures for underground or overhead wildlife crossings that did not involve species movement constraints (e.g. length) (Fagart et al., 2016). Reduction measures implemented in 2012 were integrated into the analysis. The global metric EC was also considered as the criterion to maximize at each step. The ranking of the connectivity gains from each reduction measure was generalized to the three mammals by averaging EC index values at ST and MT. 
a)

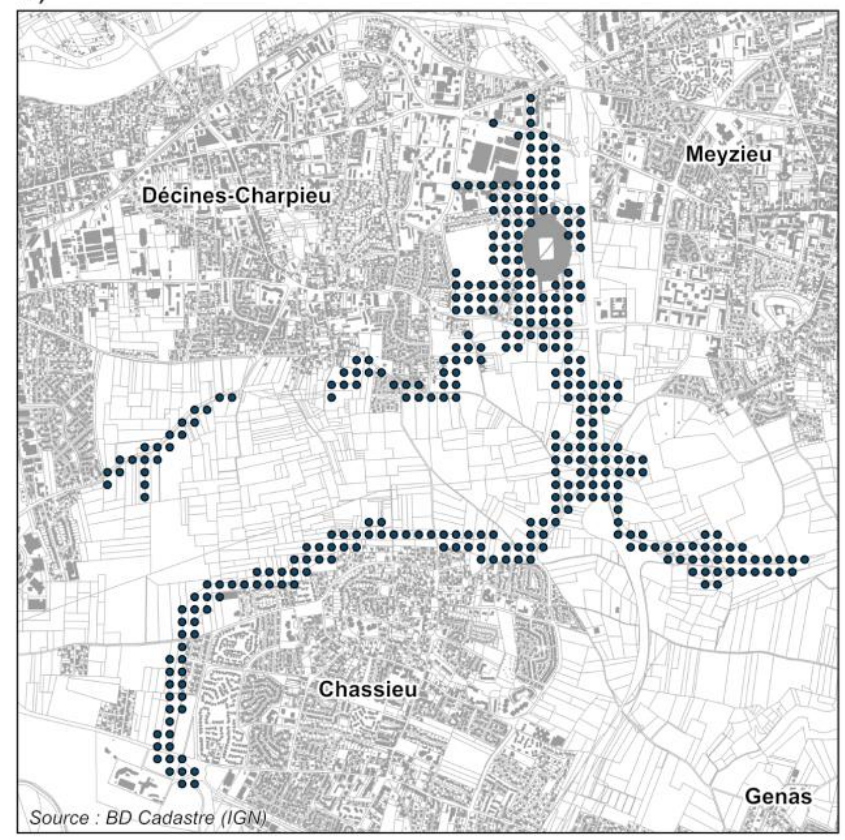

- Cells tested in the area concerned by the project b)

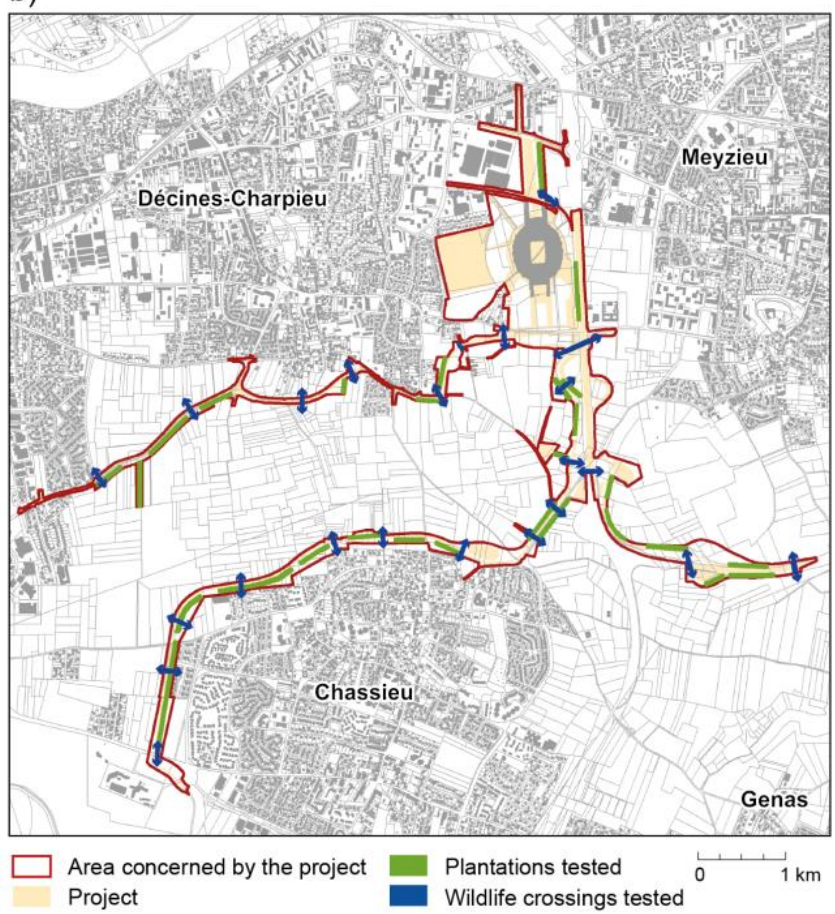

Fig. 3. Location of cells tested, using a patch addition process, within the footprint of the development project (a); location of plantations (in green) and wildlife crossings (blue arrows) considered and tested to maximize connectivity under our approach (b).

\section{Results}

\subsection{Species distribution modelling}

Of the 12 input variables previously selected, none presented a collinearity problem. After the VIF process, no variables were excluded for any species. All models performed well, with AUCs $>0.80$, TSS > 0.66 and Cohen's Kappa max $>0.69$. Several environmental variables contributed to explaining the distribution of the species in the study area (Appendix S5). For the red squirrel and the Eurasian badger, forest areas made the greatest contribution to the models (59.6\% and 36.5\%, respectively) followed by crop areas, hedges and bushes and discontinuous urban fabric for the red squirrel, and by discontinuous urban fabric, slope and tree plantations for the Eurasian badger. For the European hedgehog, crop areas made the greatest contribution to the models (39.1\%), followed by main transport network, tree plantations and hydrography. Jackknife tests on the variables yielded the same results (Appendix S6).

Based on the habitat suitability map, we identified 1,024, 1,122 and 3,595 habitat patches for the red squirrel, the Eurasian badger and the European hedgehog, respectively (Appendix S7). Total area of suitable habitats amounted to approximately $262 \mathrm{~km}^{2}$ for the red squirrel, $199 \mathrm{~km}^{2}$ for the Eurasian badger and $236 \mathrm{~km}^{2}$ for the European hedgehog.

\subsection{Habitat connectivity analysis}


A graph representing all the inter-patch links (i.e. complete graph) was constructed for each species and for all the scenarios described in Sections 2.3 and 2.4. Overall connectivity EC in the initial situation (IS; reference value) was 333.30 ha for the red squirrel, 219.53 ha for the Eurasian badger and 519.73 ha for the European hedgehog.

For each scenario, variations in habitat area $(\Delta S)$ and in $E C$ index $(\triangle E C)$ with respect to the initial situation are presented in Fig. 4. The trends were nearly identical for the 3 species, i.e., 1) the avoidance measures alone $\left(\mathrm{AM}_{1}\right)$ were not enough to achieve the objective of no net loss (NNL) of biodiversity for habitat connectivity; 2) similarly, the reduction measures $\left(\mathrm{RM}_{\mathrm{i}}\right)$ alone were insufficient 3 ) in contrast, the combination of avoidance and reduction measures (ARMT) led to a higher gain in connectivity, still low in the short term (ST) but significant in the medium term (MT), with a net positive gain in habitat connectivity for the red squirrel and the Eurasian badger ( +5.5 and +0.5 ha, respectively), but a net loss for the European hedgehog ( -2.1 ha). However, although habitat area increased MT for the red squirrel (+0.8 ha), there were still distinct losses of habit area for the Eurasian badger ( $-4.5 \mathrm{ha})$ and the European hedgehog $(-3.9 \mathrm{ha})$.

The quantitative and qualitative analysis showed lower losses when it was the $E C$ index rather than the sum of habitat area $S$ that was considered. The average difference, corresponding to the undervaluation of gains, amounted to $123.2 \%, 89.5 \%$ and $241.4 \%$ for the red squirrel, the Eurasian badger and the European hedgehog, respectively. 
a)

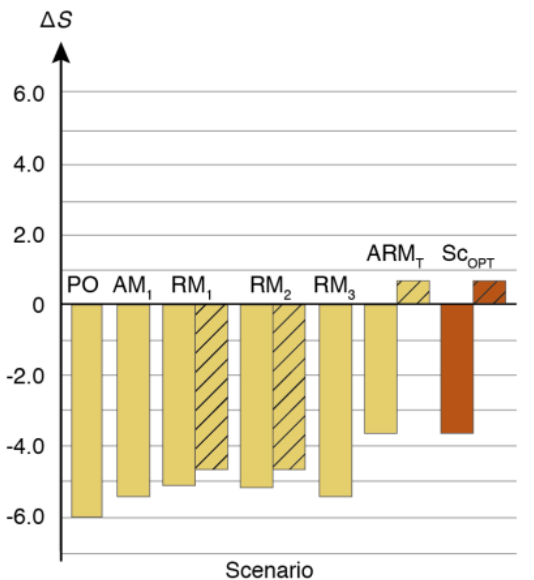

d)

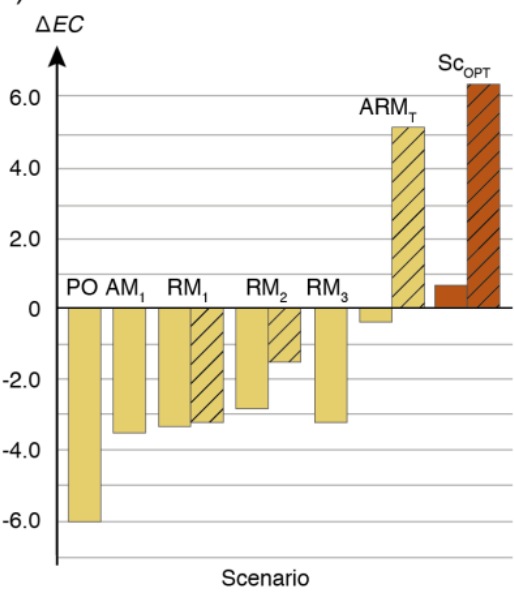

b)

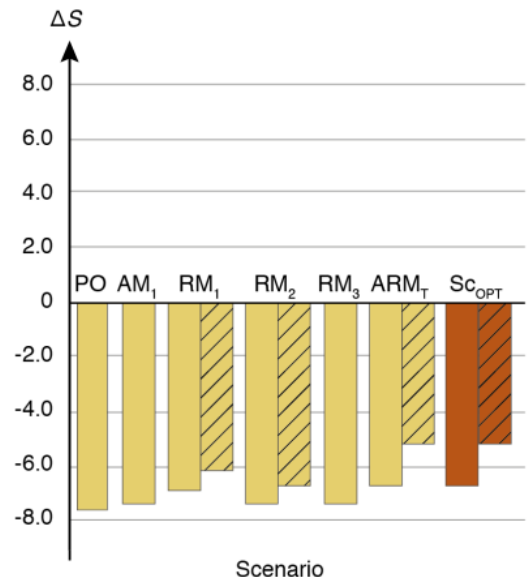

e)

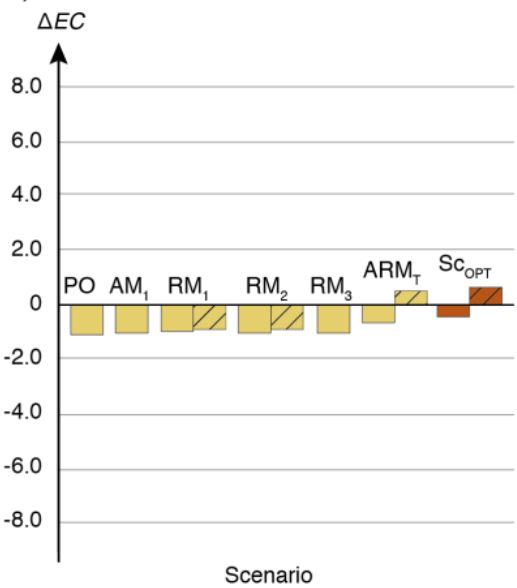

c)

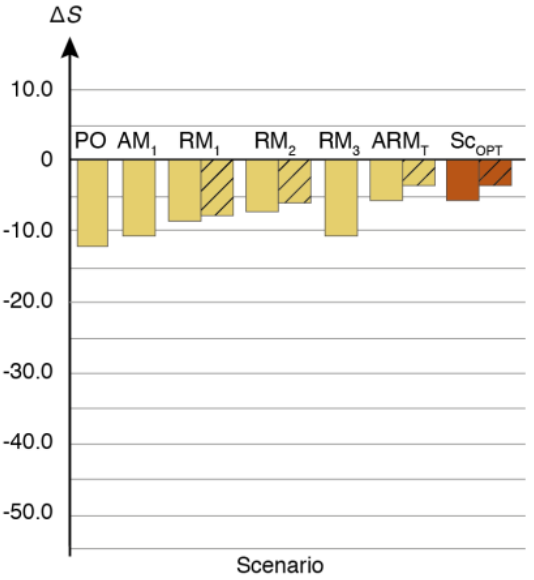

f)

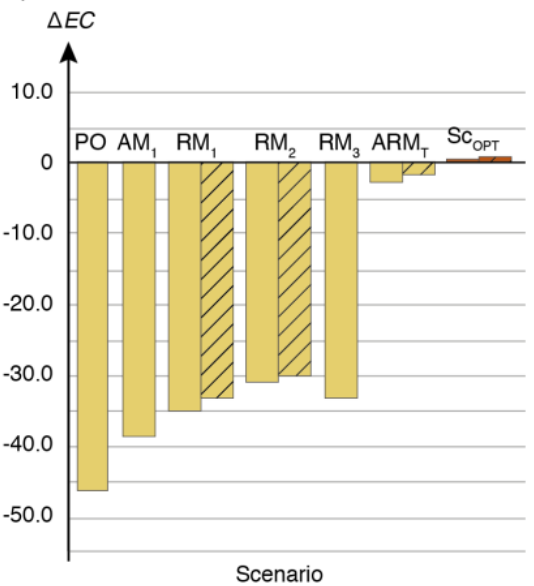

Fig. 4. Variation in habitat area $(\Delta S)$ and $E C$ index $(\triangle E C)$ for each scenario (PO: preliminary outline project, $\mathrm{AM}_{1}$ : Avoidance Measure $1=$ small forest patches avoided, RM1: Reduction Measure $1=$ small forest patches planted $+\mathrm{AM}_{1}$, $\mathrm{RM}_{2}$ : hedgerows $+\mathrm{AM}_{1}, \mathrm{RM}_{3}$ : wildlife crossings developed $+\mathrm{AM}_{1}, \mathrm{ARM}_{\mathrm{T}}=\mathrm{AM}_{1}+\mathrm{RM}_{1}+\mathrm{RM}_{2}+\mathrm{RM}_{3}$, Scopt: optimal scenario (in orange); see Section 2.5 for details) compared to the initial situation for the red squirrel (a, d), the Eurasian badger (b, e) and the European hedgehog (c, f). Results at medium-term (MT) are represented with dashed lines.

\subsection{Optimizing the location of habitat patches and reduction measures from new modelling approaches}

The patch addition process highlighted the cells where habitat creation generates the highest gain in connectivity. The results are shown in Fig. 5. Then, based on the new habitats implemented for each species in areas identified by black circles in Fig. 5d, the stepwise search for the hedgerows and wildlife crossings that would maximize the $E C$ index yielded Fig. 6. 
a)

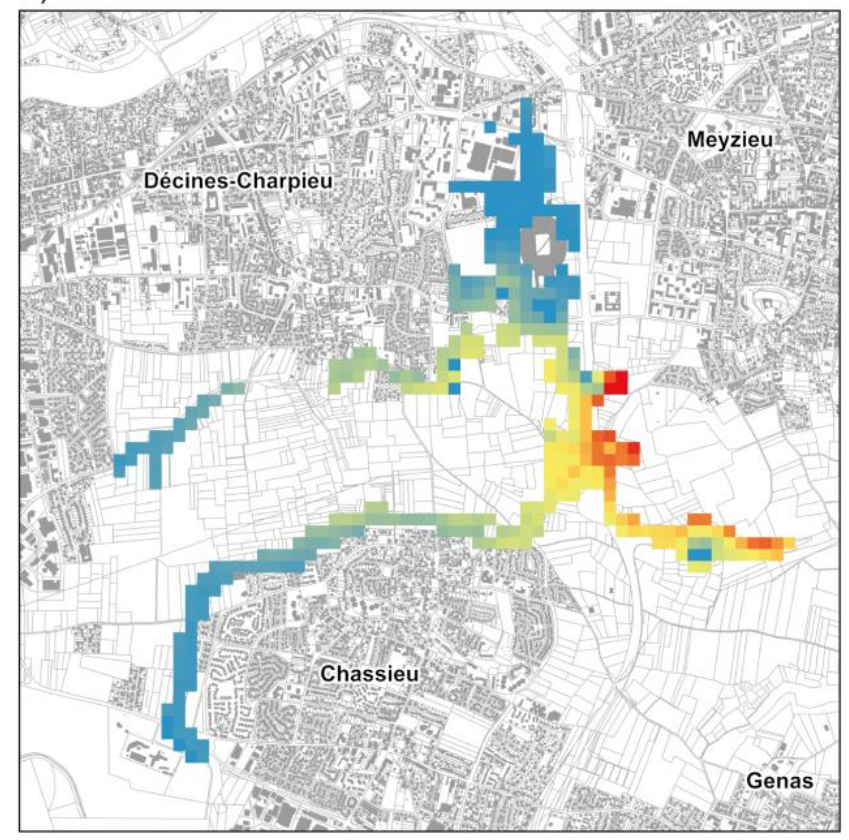

c)

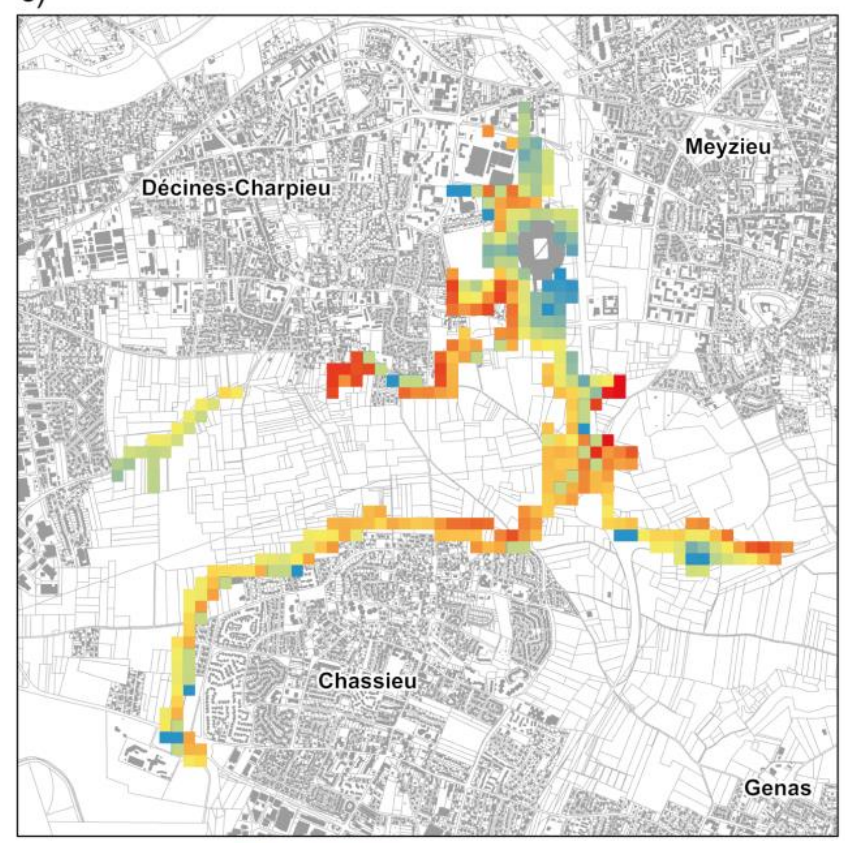

Gain in connectivity b)

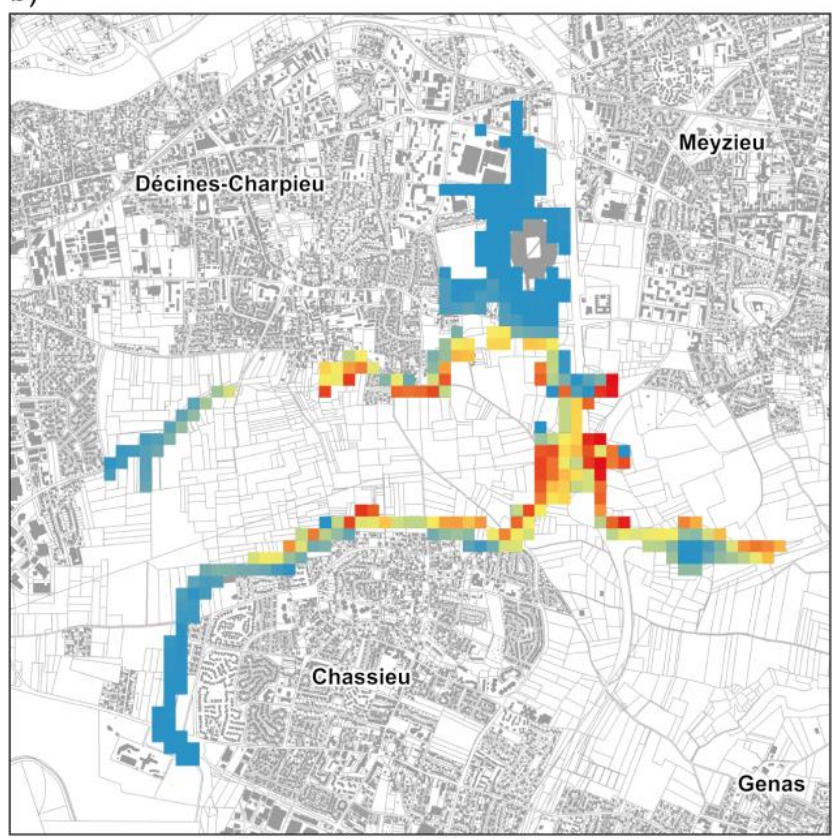

d)

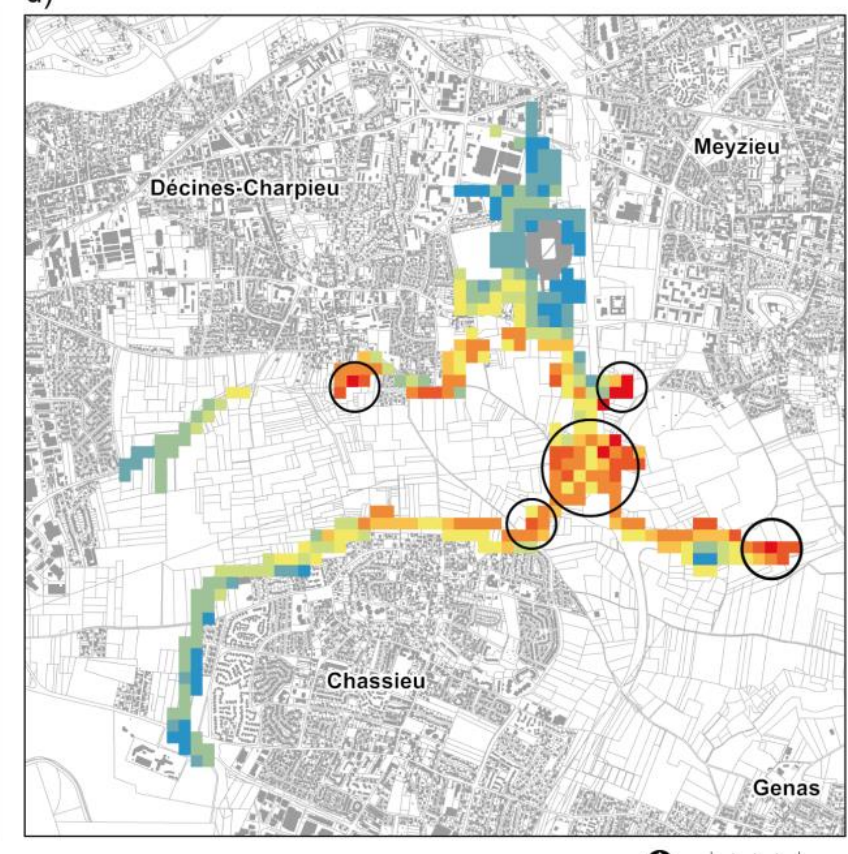

(*) $\begin{array}{llll} & & & \\ 0 & 1 \mathrm{~km}\end{array}$

Source : BD Cadastre (IGN)

Fig. 5. Potential habitat reachability gains in terms of $E C$ index following the creation of new habitat cells (with a habitat area of $0.5 \mathrm{ha}$ ) for the red squirrel (a), the Eurasian badger (b) and the European hedgehog (c). Cells were added separately, i.e. $E C$ was recomputed after each cell addition. Single-species maps were standardized and combined to show where new habitat patches benefit all three mammal species. (d) Black circles indicate areas with high potential for gain in amount of reachable habitat, selected for the creation of new habitat patches in the optimal scenario (ScOPT). 
a)

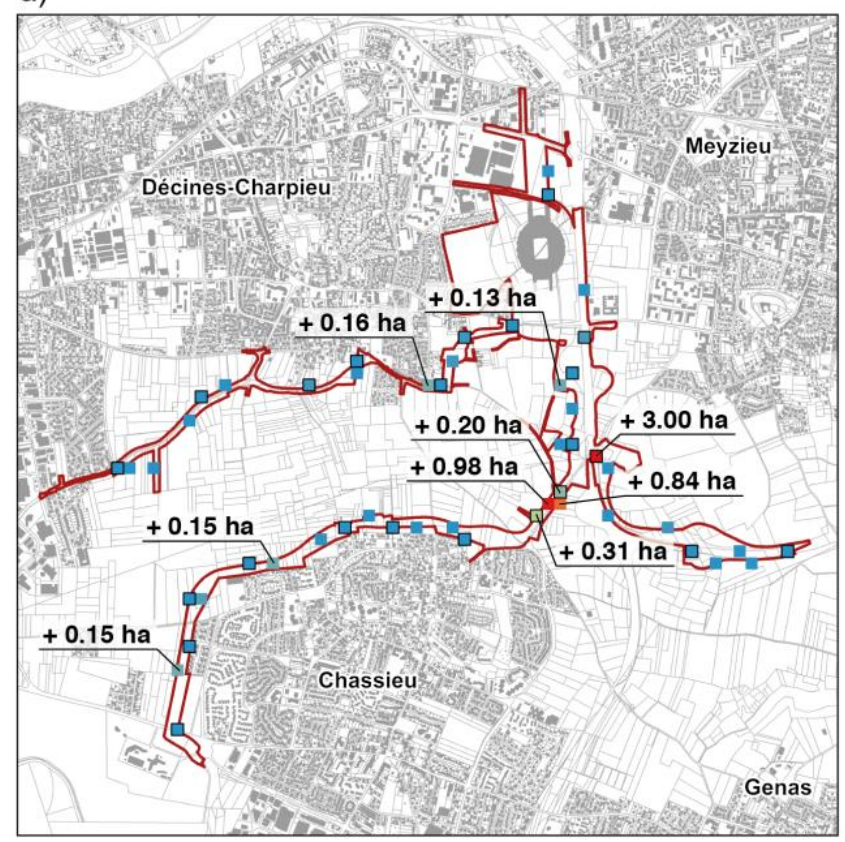

c)

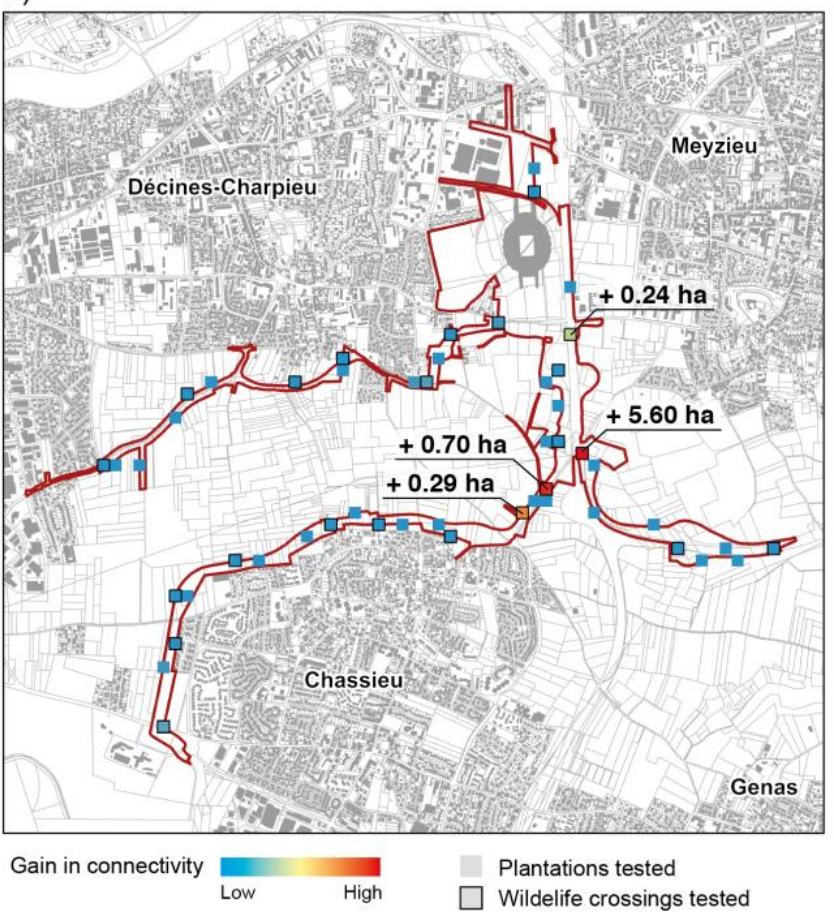

b)

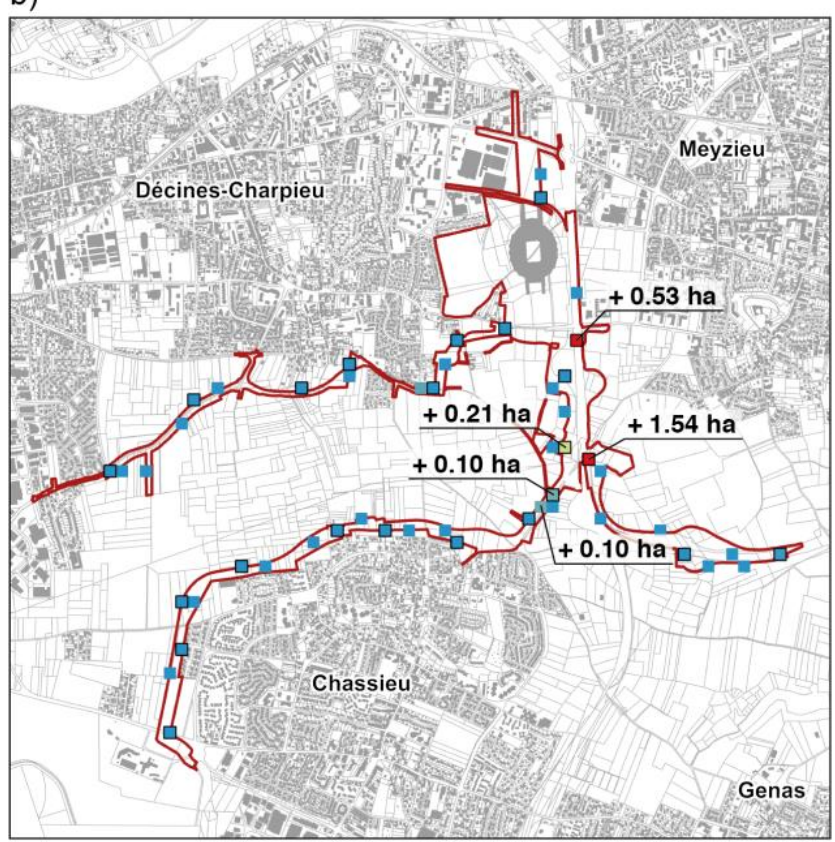

d)

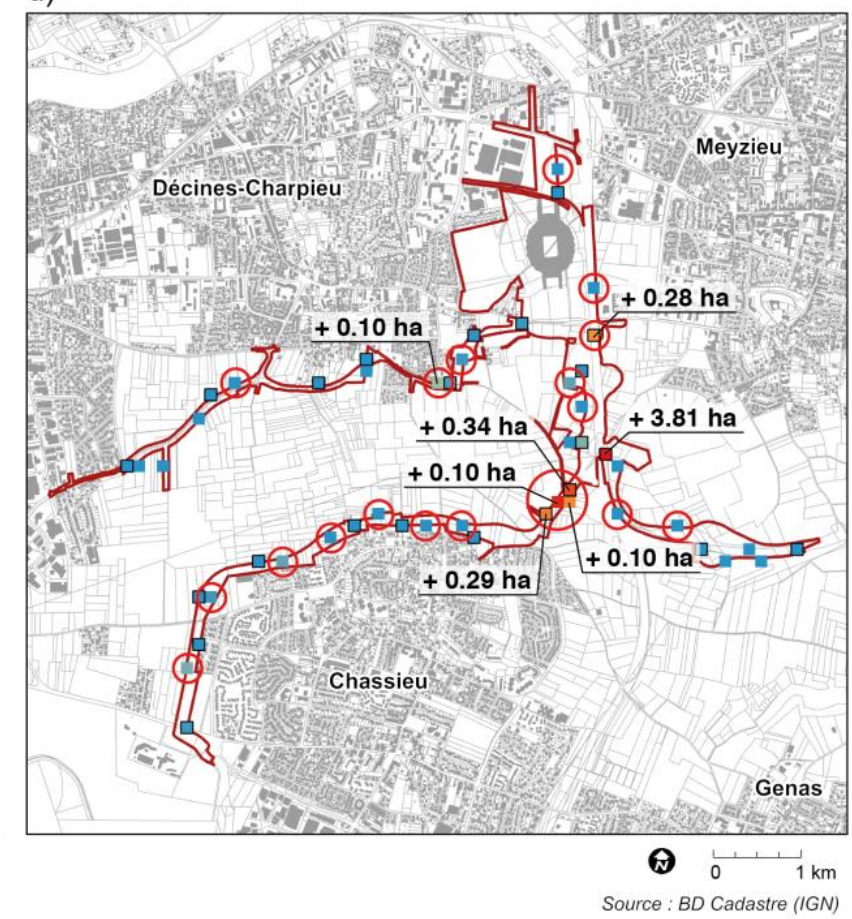

Fig. 6. Location of plantations and wildlife crossings that maximize reachable habitat for the red squirrel (a), the Eurasian badger (b) and the European hedgehog (c). Labels correspond to the average connectivity gain at ST and MT (gains > +0.10 ha). The average connectivity gain, from single-species maps, shows where adding plantations and wildlife crossings is of benefit to all three mammal species. Reduction measures selected for their high potential for gain in amount of reachable habitat to define the optimal scenario (Scopt, see Section 2.5) are identified by red circles (d).

The habitat connectivity of the optimal scenario (ScOPT) was evaluated in the short and medium term. In terms of areas equivalent to ARMT at ST and MT (see Section 2.5 and Fig. 4a, b and d), our optimization method performed better than ARMT for all 3 species. At ST, the $E C$ index gain increased by +1.19 ha, +0.21 ha and +3.39 ha for the red squirrel, the Eurasian badger and the European hedgehog, respectively. For the red 
squirrel and the European hedgehog, this achieved the objective of NNL regarding habitat connectivity. At MT and compared to ARMт, $E C$ gains were +0.68 ha, +0.09 ha and +3.15 ha for the red squirrel, the Eurasian badger and the European hedgehog, respectively, also achieving a net gain in habitat connectivity for the European hedgehog (Fig. 4).

\section{Discussion}

The approach developed here combines species distribution modelling with landscape functional connectivity modelling to quantify potential losses and gains in landscape connectivity. The goal was to better implement the mitigation hierarchy by maximizing connectivity gains at landscape scale (Tallis et al., 2015). Our findings indicate first that there is a need to take the temporal scale into account in EIA. This supports field observations by naturalists reporting that expected medium-term gains from ecological measures are not always achieved in the short term. Sometimes, losses in biodiversity are also observed. Secondly, since Huang et al. (2018b) demonstrated that connectivity decline due to the urban structure shift is not inevitable provided that the ecological network is considered in land-use planning, our approach defines the most suitable location for the reduction measures required to improve the overall amount of reachable habitat.

\subsection{Comparison of scenarios}

We used the EC index to improve habitat connectivity through the mitigation hierarchy, by reconnecting habitat patches and increasing the density of nodes and links on the species' ecological networks. The EC index has area units, making it more appropriate than the PC index (Saura and Pascual-Hortal, 2007) for quantifying and interpreting changes in habitat connectivity and comparing them to changes in the total amount of habitat at landscape scale.

This step-by-step analysis of the impact of avoidance and reduction measures ( $\mathrm{ME}_{1}$, then $\mathrm{MR}_{1}, \mathrm{MR}_{2}$, etc.) is relevant in this context and shows how each step of the mitigation hierarchy has its own importance. Our approach highlights that additional habitat patches contribute less to the amount of reachable habitat than ecological engineering, i.e. hedgerows or wildlife crossings. However, the combination of new habitat patches and corridors generates a higher biodiversity gain than separate measures. This is especially important to consider in the short term, when new plantations have not yet developed and thus are not useful to the target species (Maron et al., 2010). Some ecological measures, like hedgerows, pastures or wildlife crossings, are supposed to improve access to other habitat patches located in the surrounding landscape, because they modify matrix permeability and act as stepping stones. However, the naturalist inventories carried out in 2016 in our study site (using camera trapping and examining signs and traces) on terrestrial mammals showed that wildlife crossings were not used by the studied species, but only by domestic animals (Frapna, 2017). In 2018, faunistic studies (using camera trapping alone) showed an increase in frequentation by the Eurasian badger, but no signs of use by the two other studied species (Ecosphère, 2019). Therefore, the results predicted here support the findings of naturalists. Failure to find individuals of the studied species living in the study area 
may be explained by the fact that, while a habitat can be made theoretically accessible, probability of occurrence depends mainly on the quality of the habitats, whose attractiveness is very likely limited in the first years. Dispersal is a strategy for avoidance of poor environments, also conditioned by other species in an ecological network (Fronhofer et al., 2018). For example, Young et al. (2006) predicted that the probability of hedgehog occurrences in suburban habitats will decline in areas of high badger density. There may also be other reasons: species dispersal is multi-causal and identifying the drivers involved remains challenging. Nevertheless, ecological engineering may generate new habitats in the future if species need to move in the landscape. Small forest patches, hedgerows (provided proper hedgerow management is implemented (Graham et al., 2018), and wildlife crossings will benefit those species of terrestrial mammals vulnerable to human pressures and increased habitat fragmentation.

\subsection{Developing an optimal scenario}

The analysis of the optimal scenario, based on the best locations for implementation of habitat patches and reduction measures (hedgerows and wildlife crossings), was conducted using a two-stage process. First, the cumulative patch addition tested all potential locations, spatially restricted here to the area concerned by the development project, to prioritize the reduction measures. Then, a similar process was developed to test a set of potential land-use changes integrating plantations and wildlife crossings suitable for the species studied. While (Clauzel et al., 2015; Mimet et al., 2016) used only the second one, here for the first time we applied this two-stage approach. Our results show which areas are most suitable both for creating new habitat patches (Fig. 5) and for implementing reduction measures (Fig. 6). Our method maximizes connectivity, thereby increasing the chances of success. Note that the EC gains were greatest for the European hedgehog. This may be because our methodology was applied to a large part of the reduction measures implemented in 2012 (for instance, 3 of the 4 wildlife crossings), which appear particularly relevant to the red squirrel and the Eurasian badger.

\subsection{Implementing of offsetting}

It has been suggested that sets of small habitat patches with a large total area may have high conservation value (Fahrig et al., 2019). To further optimize the landscape configuration, our methodological framework can be extended to the land not directly concerned by the development project but owned by the local authorities available nearby. These issues can be addressed if residual impacts persist and if offsetting becomes necessary.

\section{Conclusion}

The landscape-based approach we implemented in this study helped to increase habitat connectivity in the mitigation hierarchy and to improve the design of the development project. Optimized location of the reduction measures was achieved through cumulative patch addition followed by a similar process testing a 
set of potential land-use changes and taking into account the time required for the new plantations to develop. Including in the mitigation process the time needed for new plantations to be well-developed and usable by species is a real challenge. However, this can increase the environmental efficiency of a development project, thus limiting fragmentation and habitat loss.

This study showed how habitat connectivity could be promoted in human-modified suburban landscapes for three mammal species recognized as vulnerable to human pressures. By focusing on optimizing the location of reduction measures, judicious design choices can thus increase the amount of reachable habitat within the landscape without imposing major land-use transformation. The improvement of habitat reachability for the terrestrial mammal species considered in our study may also benefit other species with similar ecological requirements. In conclusion, our methodology provides a useful tool for environmental impacts assessment studies and the application of the mitigation hierarchy by project designers and decision-makers. The study applies a "species-specific" approach which has the advantage of making the ecological network visible and understandable to all stakeholders in the territory. Several species can be treated with this kind of method, and species should be chosen with reference to conservation status at local or regional scale

Finally, further research could be applied in anticipation and planning of offsetting. Given current development policies and processes, biodiversity offsets are almost inevitable. However, the application of offsets can be significantly improved to further reduce loss of biodiversity. Our method based on optimizing the location of the mitigation hierarchy should contribute to this. 


\section{Acknowledgements}

We thank the LPO (League for the Protection of Birds) for providing species occurrence records. We thank M. Sweetko for revising the English manuscript, and the ANRT (Association nationale de la recherche et de la technologie) as well as F. Vullion and F. Theuriau (Soberco Environnement), who contributed to this research under the CIFRE agreements ( ${ }^{\circ}$ 2016/1378). 


\section{References}

Adren, H., Delin, A., 1994. Habitat selection in the eurasian red squirrel, sciurus vulgaris, in relation to forest fragmentation. Oikos 70, 43-48.

Adriaensen, F., Chardon, J., De Blust, G., Swinnen, E., Villalba, S., Gulinck, H., Matthysen, E., 2003. The application of 'least-cost'modelling as a functional landscape model. Landscape Urban Plann. 64, 233-247.

Allouche, O., Tsoar, A., Kadmon, R., 2006. Assessing the accuracy of species distribution models: prevalence, kappa and the true skill statistic (TSS). J. Appl. Ecol. 43, 1223-1232.

Antrop, M., 2004. Landscape change and the urbanization process in Europe. Landscape Urban Plann. 67, 9-26.

Arlidge, W.N., Bull, J.W., Addison, P.F., Burgass, M.J., Gianuca, D., Gorham, T.M., Jacob, C., Shumway, N., Sinclair, S.P., Watson, J.E., 2018. A Global Mitigation Hierarchy for Nature Conservation. Bioscience 68, 336-347.

Avon, C., Bergès, L., 2016. Prioritization of habitat patches for landscape connectivity conservation differs between least-cost and resistance distances. Landscape Ecol. 31, 1551-1565.

Avon, C., Bergès, L., Roche, P., 2014. Comment analyser la connectivité écologique des trames vertes? Cas d'étude en région méditerranéenne. Sci. Eaux Territ., 14-19.

Baldwin, R.A., 2009. Use of Maximum Entropy Modeling in Wildlife Research. Entropy 11, 854-866.

Bani, L., Baietto, M., Bottoni, L., Massa, R., 2002. The use of focal species in designing a habitat network for a lowland area of Lombardy, Italy. Conserv. Biol. 16, 826-831.

Bergsten, A., Zetterberg, A., 2013. To model the landscape as a network: A practitioner's perspective. Landscape Urban Plann. 119, 35-43.

Berthoud, G., 1978. Note préliminaire sur les déplacements du hérisson européen (Erinaceus europaeus L.).

Bezombes, L., Gaucherand, S., Kerbiriou, C., Reinert, M.-E., Spiegelberger, T., 2017. Ecological Equivalence

Assessment Methods: What Trade-Offs between Operationality, Scientific Basis and Comprehensiveness? Environ.

Manage. 60, 216-216-230.

Bigard, C., Pioch, S., Thompson, J.D., 2017. The inclusion of biodiversity in environmental impact assessment: Policyrelated progress limited by gaps and semantic confusion. J. Environ. Manage. 200, 35-45.

Bosso, L., Smeraldo, S., Rapuzzi, P., Sama, G., Garonna, A.P., Russo, D., 2018. Nature protection areas of Europe are insufficient to preserve the threatened beetle Rosalia alpina (Coleoptera: Cerambycidae): evidence from species distribution models and conservation gap analysis. Ecol. Entomol. 43, 192-203.

Bouniol, J., 2017. Etat des lieux de la population de Blaireau sur les îles de Crépieux-Charmy. FRAPNA Rhône, p. 23.

Ceballos, G., Ehrlich, P.R., 2002. Mammal population losses and the extinction crisis. Science 296, 904-907.

Clauzel, C., Bannwarth, C., Foltete, J.-C., 2015. Integrating regional-scale connectivity in habitat restoration: An application for amphibian conservation in eastern France. J. Nat. Conserv. 23, 98-107.

Clauzel, C., Jeliazkov, A., Mimet, A., 2018. Coupling a landscape-based approach and graph theory to maximize multispecific connectivity in bird communities. Landscape Urban Plann. 179, 1-16.

Dale, M., Fortin, M.-J., 2010. From graphs to spatial graphs. Annu. Rev. Ecol. Evol. S. 41.

De Montis, A., Ledda, A., Ortega, E., Martín, B., Serra, V., 2018. Landscape planning and defragmentation measures: an assessment of costs and critical issues. Land Use Policy 72, 313-324.

Decout, S., Manel, S., Miaud, C., Luque, S., 2012. Integrative approach for landscape-based graph connectivity analysis: a case study with the common frog (Rana temporaria) in human-dominated landscapes. Landscape Ecol. 27, $267-279$.

Delahay, R., Brown, J., Mallinson, P., Spyvee, P., Handoll, D., Rogers, L., Cheeseman, C., 2000. The use of marked bait in studies of the territorial organization of the European badger (Meles meles). Mamm. Rev. 30, 73-87.

Do Linh San, E., 2002. Socialité, territorialité et dispersion chez le blaireau européen (Meles meles): état des connaissances, hypothèses et besoins de recherche, L'Etude et la conservation des carnivores. Société Française pour l'Etude et la Protection des Mammifères Paris, pp. 74-86.

Dondina, O., Kataoka, L., Orioli, V., Bani, L., 2016. How to manage hedgerows as effective ecological corridors for mammals: A two-species approach. Agric., Ecosyst. Environ. 231, 283-290.

Driezen, K., Adriaensen, F., Rondinini, C., Doncaster, C.P., Matthysen, E., 2007. Evaluating least-cost model predictions with empirical dispersal data: a case-study using radiotracking data of hedgehogs (Erinaceus europaeus). Ecol. Model. 209, 314-322.

Duflot, R., Avon, C., Roche, P., Bergès, L., 2018. Combining habitat suitability models and spatial graphs for more effective landscape conservation planning: An applied methodological framework and a species case study. J. Nat. Conserv.

Ecosphère, 2019. Suivi de mesures compensatoires. Projet de Grand Stade. Métropole de Lyon.

Elith, J., Graham, C.H., Anderson, R.P., Dudik, M., Ferrier, S., Guisan, A., Hijmans, R.J., Huettmann, F., Leathwick, J.R., Lehmann, A., Li, J., Lohmann, L.G., Loiselle, B.A., Manion, G., Moritz, C., Nakamura, M., Nakazawa, Y., Overton, J.M., Peterson, A.T., Phillips, S.J., Richardson, K., Scachetti-Pereira, R., Schapire, R.E., Soberon, J., Williams, S., Wisz, M.S., Zimmermann, N.E., 2006. Novel methods improve prediction of species' distributions from occurrence data. Ecography 29, 129-151. 
Elith, J., Phillips, S.J., Hastie, T., Dudík, M., Chee, Y.E., Yates, C.J., 2011. A statistical explanation of MaxEnt for ecologists. Divers. Distrib. 17, 43-57.

Etherington, T.R., Holland, E.P., 2013. Least-cost path length versus accumulated-cost as connectivity measures. Landscape Ecol. 28, 1223-1229.

Fagart, S., Heurtebise, C., Quaintenne, G., Jourde, P., Micol, T., 2016. Fréquentation de buses dédiées aux passages de la petite et moyenne faune sous deux autoroutes de l'ouest de la France. Bilan des deux premières années de suivis par pièges photographiques.

Fahrig, L., Arroyo-Rodríguez, V., Bennett, J.R., Boucher-Lalonde, V., Cazetta, E., Currie, D.J., Eigenbrod, F., Ford, A.T., Harrison, S.P., Jaeger, J.A., 2019. Is habitat fragmentation bad for biodiversity? Biol. Conserv. 230, $179-186$. Foltête, J.-C., 2018. A parcel-based graph to match connectivity analysis with field action in agricultural landscapes: Is node removal a reliable method? Landscape Urban Plann. 178, 32-42.

Foltête, J.-C., Clauzel, C., Vuidel, G., 2012a. A software tool dedicated to the modelling of landscape networks. Environ. Model. Software 38, 316-327.

Foltête, J.-C., Clauzel, C., Vuidel, G., Tournant, P., 2012b. Integrating graph-based connectivity metrics into species distribution models. Landscape Ecol. 27, 557-569.

Foltête, J.-C., Girardet, X., Clauzel, C., 2014. A methodological framework for the use of landscape graphs in land-use planning. Landscape Urban Plann. 124, 140-150.

Frapna, 2017. Bilan du suivi des passages à faune des différents ouvrages de rétablissement des continuités écologiques. Métropole de Lyon.

Fronhofer, E.A., Legrand, D., Altermatt, F., Ansart, A., Blanchet, S., Bonte, D., Chaine, A., Dahirel, M., De Laender, F., De Raedt, J., 2018. Bottom-up and top-down control of dispersal across major organismal groups. Nature ecology \& evolution 2, 1859.

Galante, P.J., Alade, B., Muscarella, R., Jansa, S.A., Goodman, S.M., Anderson, R.P., 2018. The challenge of modeling niches and distributions for data-poor species: a comprehensive approach to model complexity. Ecography 41, 726-736. Galpern, P., Manseau, M., Fall, A., 2011. Patch-based graphs of landscape connectivity: a guide to construction, analysis and application for conservation. Biol. Conserv. 144, 44-55.

Gonçalves, B., Marques, A., Soares, A.M.V.D.M., Pereira, H.M., 2015. Biodiversity offsets: from current challenges to harmonized metrics. Current Opinion in Environmental Sustainability 14, 61-67.

Graham, L., Gaulton, R., Gerard, F., Staley, J.T., 2018. The influence of hedgerow structural condition on wildlife habitat provision in farmed landscapes. Biol. Conserv. 220, 122-131.

Guillera-Arroita, G., Lahoz-Monfort, J.J., Elith, J., Gordon, A., Kujala, H., Lentini, P.E., McCarthy, M.A., Tingley, R., Wintle, B.A., 2015. Is my species distribution model fit for purpose? Matching data and models to applications. Global Ecol. Biogeogr. 24, 276-292.

Hämäläinen, S., Fey, K., Selonen, V., 2018. Research paper: Habitat and nest use during natal dispersal of the urban red squirrel (Sciurus vulgaris). Landscape Urban Plann. 169, 269-269-275.

Hijmans, R.J., Phillips, S., Leathwick, J., Elith, J., Hijmans, M.R.J., 2017. Package ‘dismo’. Circles 9.

Huang, C.-W., McDonald, R.I., Seto, K.C., 2018a. The importance of land governance for biodiversity conservation in an era of global urban expansion. Landscape Urban Plann. 173, 44-50.

Huang, J., He, J., Liu, D., Li, C., Qian, J., 2018b. An ex-post evaluation approach to assess the impacts of accomplished urban structure shift on landscape connectivity. Sci. Total Environ. 622, 1143-1152.

Jiménez-Valverde, A., Lobo, J.M., 2007. Threshold criteria for conversion of probability of species presence to either-or presence-absence. Acta Oecol. 31, 361-369.

Kiesecker, J.M., Copeland, H., Pocewicz, A., McKenney, B., 2010. Development by design: blending landscape-level planning with the mitigation hierarchy. Front. Ecol. Environ. 8, 261-266.

Liu, C., White, M., Newell, G., 2013. Selecting thresholds for the prediction of species occurrence with presence-only data. J. Biogeogr. 40, 778-789.

Lobo, J.M., Jiménez-Valverde, A., Real, R., 2008. AUC: a misleading measure of the performance of predictive distribution models. Global Ecol. Biogeogr. 17, 145-151.

Macdonald, D.W., Barrett, P., 2005. Guide complet des mammifères de France et d'Europe: plus de 200 espèces terrestres et aquatiques. Delachaux \& Niestlé.

Malèvre, S., 2017. Study of the density of a Meles meles badger population in the peri-urban area of Lyon, Master Science pour l'Environnement, LBBE Lyon, p. 16.

Maron, M., Brownlie, S., Bull, J.W., Evans, M.C., von Hase, A., Quétier, F., Watson, J.E., Gordon, A., 2018. The many meanings of no net loss in environmental policy. Nature Sustainability 1, 19.

Maron, M., Dunn, P.K., McAlpine, C.A., Apan, A., 2010. Can offsets really compensate for habitat removal? The case of the endangered red-tailed black-cockatoo. J. Appl. Ecol. 47, 348-348-355.

Martensen, A.C., Saura, S., Fortin, M.J., 2017. Spatio-temporal connectivity: assessing the amount of reachable habitat in dynamic landscapes. Methods Ecol. Evol. 8, 1253-1264.

Maxwell, S.L., Fuller, R.A., Brooks, T.M., Watson, J.E., 2016. Biodiversity: The ravages of guns, nets and bulldozers. Nature 536, 143-145. 
Merow, C., Smith, M.J., Silander, J.A., 2013. A practical guide to MaxEnt for modeling species' distributions: what it does, and why inputs and settings matter. Ecography 36, 1058-1069.

Mimet, A., Clauzel, C., Foltête, J.-C., 2016. Locating wildlife crossings for multispecies connectivity across linear infrastructures. Landscape Ecol. 31, 1955-1973.

Minor, E.S., Urban, D.L., 2007. Graph theory as a proxy for spatially explicit population models in conservation planning. Ecol. Appl. 17, 1771-1782.

Moilanen, A., Van Teeffelen, A.J., Ben-Haim, Y., Ferrier, S., 2009. How much compensation is enough? A framework for incorporating uncertainty and time discounting when calculating offset ratios for impacted habitat. Restor. Ecol. 17, 470-478.

Monserud, R.A., Leemans, R., 1992. Comparing global vegetation maps with the Kappa statistic. Ecol. Model. 62, 275293.

Moorhouse, T.P., Palmer, S.C., Travis, J.M., Macdonald, D.W., 2014. Hugging the hedges: Might agri-environment manipulations affect landscape permeability for hedgehogs? Biol. Conserv. 176, 109-116.

Morris, P., 1984. An estimate of the minimum body weight necessary for hedgehogs (Erinaceus europaeus) to survive hibernation. Journal of Zoology, Lond. 203, 291-294.

Morris, P., 1988. A study of home range and movements in the hedgehog (Erinaceus europaeus). J. Zool. 214, 433-449. Muscarella, R., Galante, P.J., Soley-Guardia, M., Boria, R.A., Kass, J.M., Uriarte, M., Anderson, R.P., 2014. ENMeval: An R package for conducting spatially independent evaluations and estimating optimal model complexity for Maxent ecological niche models. Methods Ecol. Evol. 5, 1198-1205.

Naimi, B., Hamm, N.A., Groen, T.A., Skidmore, A.K., Toxopeus, A.G., 2014. Where is positional uncertainty a problem for species distribution modelling? Ecography 37, 191-203.

O’Brien, J., Elliott, S., Hayden, T.J., 2016. Original Investigation: Use of hedgerows as a key element of badger (Meles meles) behaviour in Ireland. Mamm. Biol. 81, 104-104-110.

Pascual-Hortal, L., Saura, S., 2006. Comparison and development of new graph-based landscape connectivity indices: towards the priorization of habitat patches and corridors for conservation. Landscape Ecol. 21, 959-967.

Phalan, B., Hayes, G., Brooks, S., Marsh, D., Howard, P., Costelloe, B., Vira, B., Kowalska, A., Whitaker, S., 2018. Avoiding impacts on biodiversity through strengthening the first stage of the mitigation hierarchy. Oryx 52, 316-324. Phillips, S.J., Anderson, R.P., Schapire, R.E., 2006. Maximum entropy modeling of species geographic distributions. Ecol. Model. 190, 231-259.

Quétier, F., Regnery, B., Levrel, H., 2014. No net loss of biodiversity or paper offsets? A critical review of the French no net loss policy. Environ. Sci. Policy 38, 120-120-131.

Rayfield, B., Fortin, M.-J., Fall, A., 2010. The sensitivity of least-cost habitat graphs to relative cost surface values. Landscape Ecol. 25, 519-532.

Saura, S., Estreguil, C., Mouton, C., Rodríguez-Freire, M., 2011. Network analysis to assess landscape connectivity trends: application to European forests (1990-2000). Ecol. Indicators 11, 407-416.

Saura, S., Pascual-Hortal, L., 2007. A new habitat availability index to integrate connectivity in landscape conservation planning: comparison with existing indices and application to a case study. Landscape Urban Plann. 83, 91-103.

Saura, S., Rubio, L., 2010. A common currency for the different ways in which patches and links can contribute to habitat availability and connectivity in the landscape. Ecography 33, 523-537.

Simpkins, C.E., Dennis, T.E., Etherington, T.R., Perry, G.L., 2018. Assessing the performance of common landscape connectivity metrics using a virtual ecologist approach. Ecol. Model. 367, 13-23.

Tallis, H., Kennedy, C.M., Ruckelshaus, M., Goldstein, J., Kiesecker, J.M., 2015. Mitigation for one \& all: An integrated framework for mitigation of development impacts on biodiversity and ecosystem services. Environ. Impact Assess. Rev. 55, 21-34.

Tannier, C., Bourgeois, M., Houot, H., Foltête, J.-C., 2016. Impact of urban developments on the functional connectivity of forested habitats: a joint contribution of advanced urban models and landscape graphs. Land Use Policy 52, 76-91.

Tarabon, S., Berges, L., Dutoit, T., Isselin-Nondedeu, F., 2019. Environmental impact assessment of development projects improved by merging species distribution and habitat connectivity modelling. J. Environ. Manage. In press. Team, R.C., 2017. R: A language and environment for statistical computing. Vienna, Austria: R Foundation for Statistical Computing; 2016.

Thuiller, W., Lafourcade, B., Engler, R., Araújo, M.B., 2009. BIOMOD-a platform for ensemble forecasting of species distributions. Ecography 32, 369-373.

van de Poel, J.L., Dekker, J., van Langevelde, F., 2015. Dutch hedgehogs Erinaceus europaeus are nowadays mainly found in urban areas, possibly due to the negative effects of badgers Meles meles. Wildl. Biol. 21, 51-56.

VINCI Autoroutes, L.F.C., 2016. Synthèse du retour d'expérience des aménagements et des suivis faunistiques sur le réseau VINCI Autoroutes. VINCI Autoroutes.

Wauters, L., Casale, P., Dhondt, A.A., 1994. Space use and dispersal of red squirrels in fragmented habitats. Oikos, 140146.

Wauters, L.A., Verbeylen, G., Preatoni, D., Martinoli, A., Matthysen, E., 2010. Dispersal and habitat cuing of Eurasian red squirrels in fragmented habitats. Popul. Ecol. 52, 527-536. 
Young, R., Davison, J., Trewby, I., Wilson, G., Delahay, R., Doncaster, C., 2006. Abundance of hedgehogs (Erinaceus europaeus) in relation to the density and distribution of badgers (Meles meles). J. Zool. 269, 349-356.

Zeller, K.A., McGarigal, K., Whiteley, A.R., 2012. Estimating landscape resistance to movement: a review. Landscape Ecol. 27, 777-797. 